Journal of Undergraduate Ethnography Vol. 7 No. 1 67-91

ISSN 2369-8721

\title{
Office Places, Work Spaces: An Ethnographic Engagement with the Spatial Dimensions of Work
}

Robert L. Ordelheide 


\section{Abstract}

Have you ever been curious to know more about how people engage with their place of work? This article explores the spaces and places of a scientist's academic office. It draws on four weeks of in-depth participant observation, interviews and visual analysis at the University of Cape Town to create an in-depth understanding on how the office, as a thing, shapes behaviour. Theoretically, this paper draws on phenomenological thought, Henri Lefebvre's (1991) theory on the social production of space, and Tim Ingold's (2000) ideas on the 'taskscape' to analyse the spatial components of work within and beyond the academic office. It argues that the office is far more intricate than just the site of non-manual labour. Indeed, there appears to be a unique way in which the performance of one's academic discipline disciplines space.

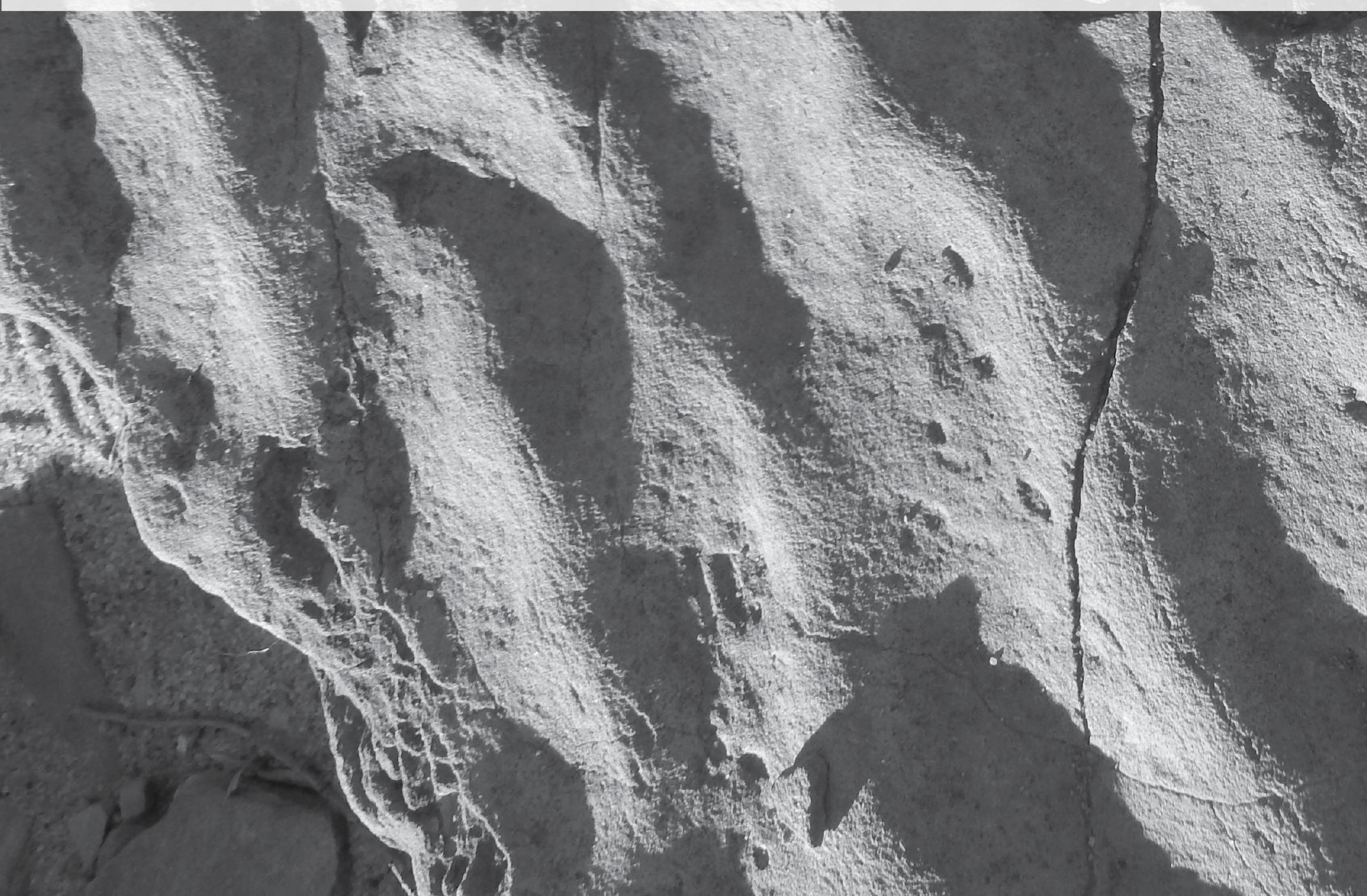


In reaching the conclusion of my undergraduate career, I have come to realize that a strong understanding of space is critical to most ethnographic engagements. Anthropology has taught me that space is complex. Space is more than just a three dimensional plane, as often conceptualized in Euclidean thought. Moving towards a nuanced understanding drawn from Pierre Bourdieu (1989), I have learnt that space is a system of relations. Space is the invisible and complex milieu that binds people, things and places together. As one moves through the world, one will inevitably move through a multitude of spaces: the space of one's home, the space of one's neighbourhood or city, one's personal space, one's intellectual or learning space, or one's workspace. Though these spaces may correspond to specific tangible points on the landscape, all are socially constructed.

The spatial dimensions of the place of one's work are of particular interest in this article. Contemporary workspaces come in a multitude of styles, shapes, sizes and locations. In the present era of hyper-connectivity, e-commerce and computer-aided record-keeping, most readers will be familiar with the office as the quasi- ubiquitous location of work. Within the air-conditioned warrens of current office environments, ritualized non-manual labour is ordinarily done on computers, people are connected to vast quantities of information via the internet, and smart phones and tablets synchronize with computers to make work transportable. From this context, one can view the office as a space ordinarily reserved for a person whose job requires the use of the mind, to think, rather than the use of their hands or physical strength (Wallman, 1979).

An ethnographic engagement with the office is an important endeavour for two reasons. Firstly, drawing inspiration from Nikil Saval (2015), I suggest that 'work' is a deeply cultural phenomenon and therefore so is the office. 'Culture' is the performance and practice of everyday life which produces meaning for individuals, or groups (Garuba and Raditlhalo 2008). What sort of routine and ritualized behaviour might one find within the spaces and places of work? Secondly, drawing from Christopher Baldry (1997), an analysis of the office can illuminate the broader hierarchical and organizational structure of one's place of employment. Where one sits, how big one's office is, and what sort of objects are present within one's office all speak volumes on how people organize themselves across space.

\section{Background and Research Methods}

In 2015, driven by this interest in the spatial dimension of work, I embarked on a month of ethnographic fieldwork as a basis for an analysis of office spaces on my own campus at the University of Cape Town, South Africa. This university was originally founded in 1829 as the South African College, and is South Africa's oldest higher learning institution (Phillips 1993). The university's origi- 
nal benefactors envisioned an academic institution that reflected a version of their own alma maters, the colleges at Oxford and Cambridge universities. Well into the twenty-first century, the University of Cape Town's 'Oxbridge' characteristics remain firmly imprinted on much of the visual and spatial culture of the academy (Schmahmann 2011). Being the archetypal 'English' academy at the foot of Africa creates a highly paradoxical and sometimes tumultuous environment for staff and students to navigate.

Over the course of this fieldwork, I followed the daily routines of two academic staff members and one senior $\mathrm{PhD}$ student located in three different faculties of the university. In total, I spent approximately a week and a half with each interlocutor. While two of my interlocutors were based in the South African College of Music and the School of Language respectively, this essay details my experience with my third interlocutor, named 'Jason' (a pseudonym), who is a plant scientist and PhD candidate in the School for Biological Sciences.

In order to operationalize this research, I drew upon the standard suite of ethnographic research methods (e.g. participant observation, photography, mapping, interviews and journal keeping) to gain a deeper understanding of the phenomena I encountered in the field. The benefit of using a multi-method approach is that I had the opportunity to tailor my techniques to suit the ever-changing dynamics in the field.

With regards to participant obser- vation, I first spent a period developing rapport with my interlocutors. From there, I inhabited the academic office space alongside my interlocutors, observing and interacting with them during the normal courses of their daily routines. I kept a fieldwork notebook on my observations which was used as an analytical tool to identify the recurring themes, patterns and disjunctures found in the field. Within the fieldwork journal, I kept a close record of times of office use, patterns and purposes of use, visitors, consultations, and times working alone. I also made special notations for open and closed doors, seating arrangements, corridor conversations, drop-ins versus appointments, and any other valuable social interactions when and where they occurred. I tried to sit in on as many instances of office use as possible, but sometimes the ebb and flow of my interlocutor's daily work routine required him to do some work outside the confines of the office.

One of the strengths of participant observation is the ability to bear witness to spontaneous events which may occur in an interlocutor's everyday life. That said, one of the weaknesses that I encountered with participant observation is that my presence in the room changed the behaviour of my interlocutors. I would walk into the office with my notepad and pen with the intention of observing the work routines and happenings within the office space. My interlocutors' natural reaction was to give me their full undivided attention. This attention was excellent for interviewing, but problematic for other 
observational work. I was never fully able to circumnavigate the problems my presence in the field created for me.

Interviews are another method I used in my analysis of the space of work. I made use of both unstructured and semi-structured interviews. For unstructured interviews, I gave my informants the latitude to discuss what is important to them in their relationship to their working space. The very point of unstructured interviews is that there is no structure or control; just the interlocutor and I talking about whatever came to mind. I would then transcribe keywords, strength of the interview method lay in its ability to garner rich first-hand descriptions and narrative directly from an interlocutor. That said, the weakness of the interview technique is in the potential for an interlocutor to provide unreliable information. It is also very time-consuming.

Finally, I made use of the visual research techniques of photography and maps to document my fieldwork experience. I used a digital camera to capture the space, artefacts and architecture in photographs. Moreover, I also made hand-drawn maps to reconstruct the field

\section{"This research represents an attempt to force the ethnographic gaze back upon the academy; to make the familiar surrounds of the academy unfamiliar; and to analyse the privileged position that academics hold as the central cog in the university knowledge production machine."}

thoughts and ideas at the end of the day for use in a more structured interview. For semi-structured interviews, I designed my questions in advance but also left these questions open-ended so I could probe where needed. I audio-recorded interviews so I could refer back to transcripts, and also typed these up shortly after the interviews had concluded. Finally, as interviews include more than just the words spoken, I kept a journal to note voice range, expressions and gestures in the natural flow of the dialogue. The spaces in my notes. One of the weaknesses in using visual research techniques, and fieldnotes for that matter, is that photographs, fieldwork journals and maps are artefacts in their own right. They are created, or fashioned, by the researcher. As such, they feature the researcher's perspective and selective interpretation of what really happened. One of the advantages of using these methods is that they provide a visual artefact as a point of reference to remember and reflect upon, and offer an additional analytical tool for 
the development of a thick description account of events in the field. Several of the photographs have been included in this article. Finally, it must also be noted here that this research was conducted with strict adherence to the ethical guidelines established by Anthropology Southern Africa (2005). As a result, I sought informed consent from my interlocutors at every step of the research process and was mindful to ensure that no harm came from this research process.

Beyond my interest in the spatial dimensions of work, my motivation to write on this seemingly mundane topic was drawn from concern about how my academic discipline had been negatively leveraged by previous practitioners. The ongoing critique post-colonial thinkers have waged against African anthropology is that its practitioners have often been far too quick to study the lives of Africa's marginal and disempowered peoples without being fully cognizant of just how exploitative and disempowering the research process can be (Nyamnjoh 2012). As a student in the final stages of my undergraduate career, I felt uncomfortable with my privileged position and the prospect of going out into the city and placing some unknown person under my ethnographic gaze. Rather, drawing inspiration from Nyamnjoh (2012, 70), I wanted to practice a mindful, responsible and transformed anthropology that would be bold enough to "study up" and ethnographically analyse power and privilege. After all, "all people today are equal in their right to the burden of being studied by some or other anthropologist" (Miller 2010, 10). This research represents an attempt to force the ethnographic gaze back upon the academy; to make the familiar surrounds of the academy unfamiliar; and to analyse the privileged position that academics hold as the central cog in the university knowledge production machine.

Mindful of the context above, and inspired by Bourdieu's (1989) idea that space is a system of relations, this research seeks to examine how space, place and people interweave in the context of an academic office. Through ethnographic inquiry into the use of an office, and employing an array of literature and theory, this article explores the daily work life of a plant scientist, university inhabitant and office dweller. In the first part, I will discuss Lefebvre's (1991) ideas on space and then call upon Edward Casey's (1997) argument in favour of place to set the scene. In the second part of this essay, I call upon Maurice Merleau-Ponty (2007) and other phenomenological thinkers to articulate how one might perceive and embody the physical environment which, in turn, informs human behaviour. In the third section, I will draw upon Tim Ingold's (2000) notion of the 'taskscape' to illustrate how space, place and embodiment are intrinsically linked in the process we know as 'work'. In the fourth section, I present ethnographic descriptions of the eight days spent in the office (e.g. the field) with Jason, the interlocutor. In the fifth and final section of this essay, I tie all the aforementioned information 
together to argue in favour of an understanding that space is indeed a social construction that mediates one's behaviour and one's relation to place. However, I critique the Lefebvrian understanding of space by arguing that one must not fetishize space at the expense of place. As argued below, place is an equally important construct that deserves recognition in theory and ethnographic practice. I conclude with thoughts on how one might be able to build upon this research project in the future.

\section{Theoretical Framework}

\section{Space and Place}

First, this research draws on Lefebvre's (1991) seminal work The Production of Space. Lefebvre was deeply influenced by Marxist theory; as a result, one sees a heavy emphasis on the idea of 'production'. Lefebvre $(1991,26)$ writes, "(social) space is a (social) product". By this, Lefebvre means that "space is permeated with social relations; it is not only supported by social relations, but it also is producing and produced by social relations" (2009, 186).

Lefebvre suggests that there are an "indefinite multitude of spaces, each one piled upon, or perhaps contained within the next: geographical, economic, demographic, sociological, ecological, political, commercial, national, continental, and global. Not to mention nature's (physical) space, the space of (energy) flows, and so on" $(1991,81)$. With Lefebvre's notion of space, one sees that space cannot be 74 divided by physical barriers or walls. "Social spaces interpenetrate one another and/or superimpose themselves upon one another. They are not things which have mutually limiting boundaries and which collide because of their contours or as a result of inertia" (Lefebvre 1991, 87). An example of this would be the space of an office contained within four walls. Although physical barriers exist in the form of walls, the space of the office may extend beyond the walls into the adjacent corridors or other offices in a building. In essence, social space is fluid, able to circumnavigate the physical boundaries that lie in its path.

Also, according to Lefebvre (1991), space is neither passive nor a vacuous container. Two points follow from this statement. Firstly, space always embodies social meaning. The very notion of an empty space later to be filled with social life is a social construct itself - or a representation of space (Lefebvre 1991). According to Lefebvre, space is simply never empty. Secondly, space should be seen as organic and alive, "[space is] an 'active moment' in social reality, something produced before it is reproduced, created according to definite laws, conditioned by a definite stage of social development" (Merrifield 1996, 107). In my reading of Lefebvre (1991), I interpret his notion of space as a social performance or system of relations which completely encircles humanity and is filled to the brim with meaning. Space simultaneously produces humanity, and is critical in producing human perception and behaviour. In my 
view, space is critical to the analysis of the office.

What is problematic with Lefebvre's (1991) understanding of space is that he appears to avoid the notion of 'place', or one's geographical location within the milieu of space. As Casey (1997) argues, one of the greatest scandals of Western philosophical thought since Rene Descartes has been to relegate the notion of 'place' to the intellectual dustbin. In Casey's (1997, 295, emphasis in original) line of argument,

space forms a twosome, an uneven doublet, with place, its odd and incongruous other. The twoness is not that of two things, or even of two of a kind, but instead that of two quite variant kinds which nevertheless coexist in all their disparity and cannot seem to do otherwise.

This indicates that as well as drawing on Lefebvre, one also needs to make allowance for the notion of 'place' - 'place' being a concrete position within the shapeshifting social landscape mentioned above. The necessity of both 'space' and 'place' appears to be corroborated by Ingold $(2000,192)$ who states:

a place in the landscape is not 'cut out' from the whole, either on the plane of ideas or on that of material substance. Rather, each place embodies the whole at a particular nexus within it, and in this respect is different from every other.

Edward Relph $(1976,3)$ similarly argues that "a place is not just the 'where' of something; it is the location, plus everything else that occupies that location seen as an integrated and meaningful phenom- enon".

In my own interpretation, I argue in favour of both concepts of 'space' and 'place'. Using the example of the University of Cape Town, an office, the lecture theatre, the library, and the bookshop are all places. They are all points on the landscape where one can be physically emplaced. Yet, these places are also spaces in that they produce, and are produced by, social behaviour, and are not necessarily fixed, but form part of the larger fluid social body of the university. One may dwell within a building on campus, but one is not necessarily contained by a building. I see Lefebvre's (1991) space as the glue that holds a constellation of places together. I show through my experience in the field that offices are places, but the process of 'work' has a spatial component which extends far beyond the confines of the office.

Being-in-the-office: The phenomenological approach

Building on Lefebvre's (1991) ideas on space, and Casey's (1997) arguments in favour of place, are the concepts of phenomenology and embodiment. Phenomenological theory is based upon the central thesis of the 'primacy of perception'. According to Merleau-Ponty (2007), perception is consciousness: people perceive social and material occurrences through their bodies, then instantaneously and continually reflect on and analyse these perceptions to inform their embodied selves. Thomas Csordas $(2002,61)$ clarifies this position by pointing to the fact 
that perception begins in one's body and ends in the objects one perceives. Merleau-Ponty "wants us to step backward from the object and start with the body in the world" (Csordas 2002, 61). Phenomenological theory, in its essence, lays the groundwork for an understanding of a body that is ambiguously positioned as both an object and a subject. Human perception starting from the body is our main method for analysing and engaging with the world around us.

Stemming from the phenomenological foundation that Merleau-Ponty (2007) and Csordas (2002) provide, Miles Richardson (2012) presents the idea of being-in-the-world - a phenomenological account of the intersubjective relationship between the individual and the material world. Richardson points to symbolic interactionism, a sociological concept, which "argues that people respond to objects on the basis of what those objects mean and that the meaning of those objects arises out of the negotiated experience of social interaction (Richardson 2012, 75; also see Low 2003). He argues that material culture, for instance, that of an academic office with all of its contents, becomes a "series of collapsed acts, the signs of what would happen if the acts were carried to completion - with the ability to make artefacts, we can fix our experience much in the same manner that text fixes discourse" (Richardson 2012, 75).

Understanding that material culture is the physical expression of the world one lives in, Richardson hypothesizes that there are three analytically distinct steps to being-in-the-world. First, one would assess the material component of one's surroundings through sensory perception. "In this, material settings resemble a series of semantic domains, as people enter them; provide a preliminary understanding of the interaction going on around them" (Richardson 2012, 78). The second step is the interaction component. In this step, as people interact with the material world and with each other, their behaviour becomes meaningful "to the extent that it incorporates or challenges their initial understanding of what is happening around them" (Richardson 2012, 80).

The third step is the image component, which incorporates the material culture, the acts, the gestures, and the interactions happening within this space, and objectifies the image of all these components as representative of what ought to happen in this specific social setting. It is the "transfer of the 'what' of the ongoing social experience onto the 'where' of the material setting” (Richardson 2012, 85 , emphasis in original). In essence, the social situation becomes physically fixed in a material place. Being-in-the-world is dependent on one's ability to read one's surroundings and place this information within a milieu of social and material understandings. Thus, being-in-the-world is the subconscious process that informs embodied social behaviour.

In short, through the process of perceiving, a person will embody the socially constructed meanings imbued in their 
surrounding place or environment. They reflect the materiality of place through their actions, behaviours, and attitudes. Drawing inspiration from Richardson's (2012) work on phenomenology and space, the term I will use for embodying space is being-in-the-office. In the ethnographic section of this article, I show that Jason has a very specific way of being-inthe-office.

\section{Taskscapes}

Tying space and place together with the phenomenological approach of beingin-the-world is Ingold's (2000) notion of 'taskscapes'. Of the human behaviours I witnessed while watching my interlocutors' being-in-the-office, the most obvious behaviour is 'work'." By work, I mean "making things and performing services which are of value to oneself, as well as to others" (Applebaum 1992, x). However, 'work' is a catch-all term and the series of actions and behaviours underpinning work requires further analysis.

One way to understand the complexity of work is by viewing 'work' as a series of 'tasks'. According to Ingold (2000 195, emphasis in original), a task can be defined as:

any practical operation, carried out by a skilled agent in an environment, as part of his or her normal business of life. In other words, tasks are the constitutive acts of dwelling. No more than features of the landscape, however, are tasks suspended in a vacuum. Every task takes its meaning from its position within an ensemble of tasks, performed in series or in parallel... It is to this entire ensemble of tasks... that I refer by the concept of taskscape.

A pertinent aspect of Ingold's (2000) idea of taskscape is the interdependent relationship between task and place. I interpret Ingold's argument as suggesting that a task, in an ensemble of tasks, may vary depending on the features of the landscape. Ingold (2000 198, emphasis in original) writes:

Human beings do not, in their movements, inscribe their life histories upon the surface of nature as do writers upon the page; rather, these histories are woven, along with the life-cycles of plants and animals, into the texture of the surface itself. Thus the forms of the landscape arise alongside those of the taskscape, within the same current of activity.

A practical example of the relationship between task and place that will be highlighted below is that an individual may carry out the task of computer-based work in an office, but will engage in an entirely different set of tasks in the laboratory, or out on the mountain while they conduct their field research. In essence, I argue that the taskscape is the phenomenologically based spatial component of 'work' described in the previous section.

Another pertinent point of Ingold's (2000) is that tasks are indicative of a person's social identity. "The tasks you do depend on who you are, and in a sense the performance of certain tasks makes you the person who you are" (Ingold 2000, 325, emphasis in original). Furthermore, these tasks are never performed in isolation, but exist within 
the context of the taskscape, that is, "the totality of tasks making up the pattern of activity of a community" (Ingold 2000, 325). When observing a person engaging in a set of tasks which forms part of his or her taskscape, one should take note of whether this task is emplaced within a certain physical location, and whether any other individuals are aiding, engaging, or participating in the task at hand. In light of this understanding, and in relation to this case study, one should question what tasks are exclusive to the office. Are there any tasks found outside the office in the workplace landscape? Are any of these tasks done in solitude, or shared with peers? Having outlined this theoretical framework, I will now delve into ethnographic description of Jason and his office.

\section{Ethnographic Case Study: The Office of a Plant Sci- entist}

It was a clear, windy and unusually crisp Cape Town morning. It was the 24th of June, 2015, and I had an appointment to meet with one of my interlocutors at his office on campus. Jason was a PhD student in the Department of Biological Sciences and had been studying at the University of Cape Town for roughly thirteen

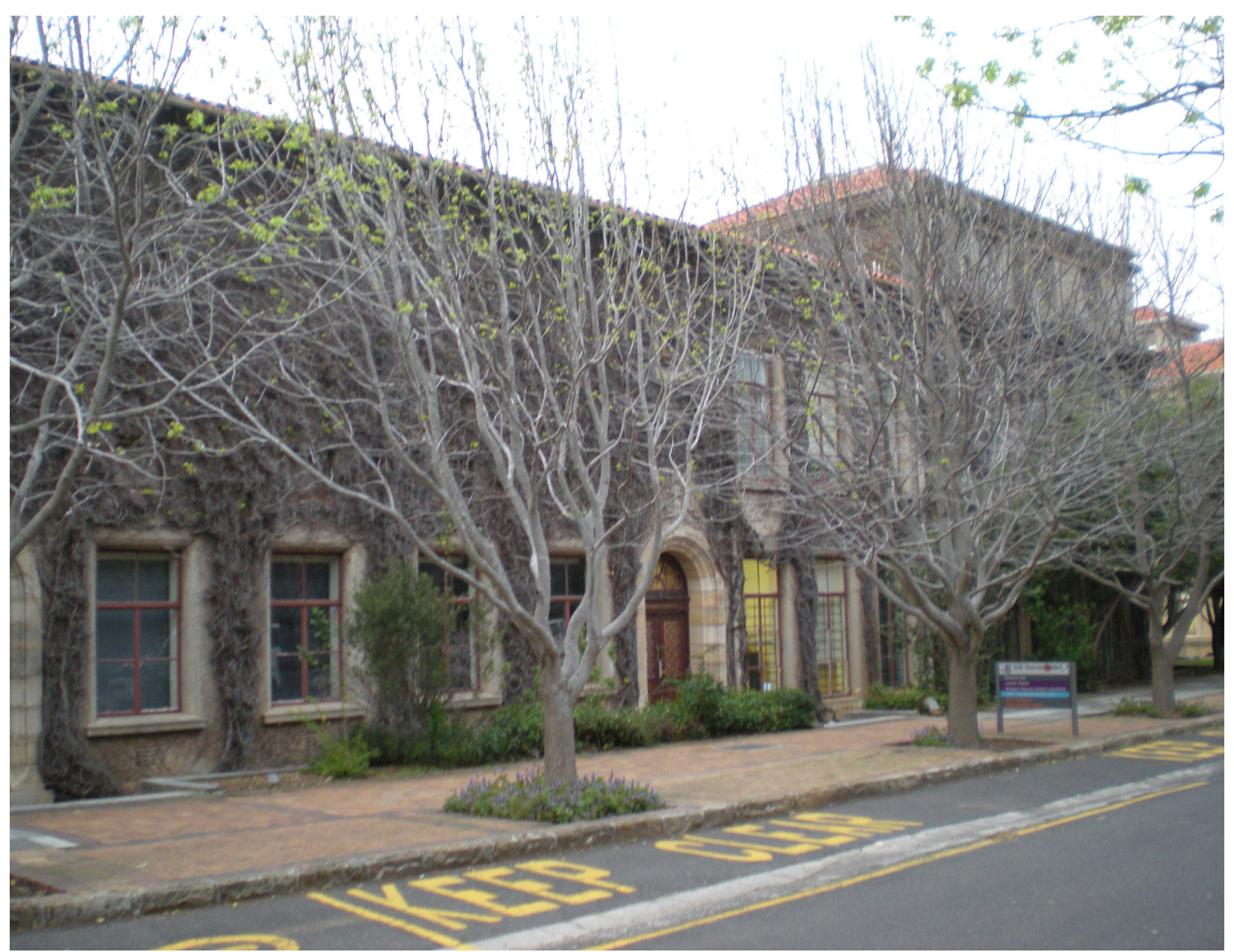

Figure 1. The exterior of the H.W. Pearson building as seen from the sidewalk along University Avenue. Date captured: 3 July, 2015. 
years. I parked my car on the road that runs above the university rugby fields and walked up the grand staircase towards Jameson Hall, the dominant architectural icon and central axis of the University of Cape Town upper campus.

I turned right down University Avenue, heading towards the H.W. Pearson Building, otherwise known as the 'old botany building'. According to Howard Phillips (1993), the H.W. Pearson building has been the home to the biological sciences faculty since they relocated to the university's upper campus in 1929. At street level, the H.W. Pearson building looks like a modest two-story facility, with a third level added to the north and south turrets (figure 1). The exterior of the building matches many of the other buildings on campus: red tiled roofs, stucco-plastered walls, red metal win-

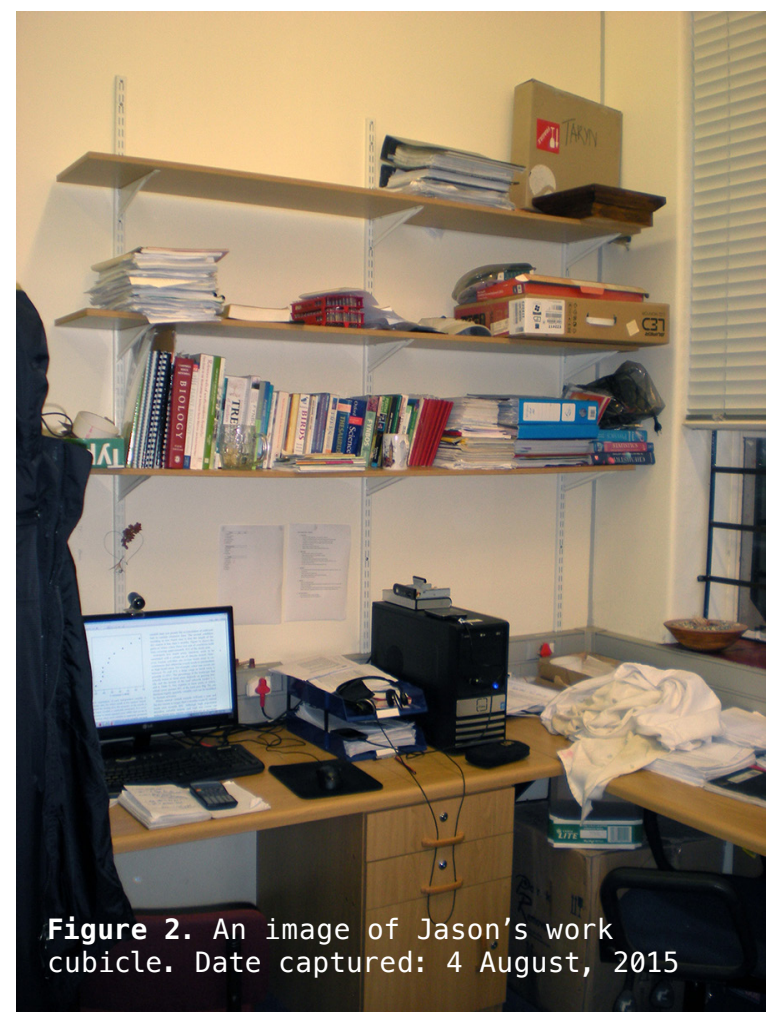

dows, and dark wooden doors - much of the exterior covered by decades of growth of ivy. H.W. Pearson, like many of the other buildings on upper campus, was built on a slope - as a result, there is an additional floor beneath the level of University Avenue that houses laboratories, storage space, offices, and a thoroughfare to the glasshouse that is often used for plant experiments.

On this morning, I entered H.W. Pearson and was immediately struck by the artwork lining the beige-plastered hallways - botanical illustrations in thick black picture frames (for example, hand-drawn artworks depicting an anatomically correct plant specimen). Jason stated on another afternoon in July that these illustrations were all hand drawn by undergraduate students in the department. Each year the best botanical illustration is chosen by the department and displayed in the hallway for everyone to enjoy. From the small foyer, I turned the corner and made my way down a corridor that was flanked by a light-well on one side and a row of closed office doors on the other. The office doors were solid with polished brass fittings, all shut as to protect their occupants from the goings-on outside. I eventually managed to find the door with a name tag bearing Jason's name, as well as four other names I did not know. I knocked, and let myself in. Jason works in a shared office space with four other senior postgraduate students. Two walls of this office are flanked with cubicle work stations. The far wall contains a desk-height countertop and 
a shared printer which is backed by two very large windows that look upon the passing foot traffic on University Avenue. Sitting abreast to the wall with the office door is a large filing cabinet and a shared office refrigerator. The room itself is slightly larger than fifteen square meters. Each office occupant has their own cubicle of approximately three square metres. Each cubicle is divided from the next by wooden panels with green fabric bulletin board. Jason's cubicle is in the back corner of the room adjacent to the printer and windows, with Jason's computer facing the interior of the room, while he faces the wall (figure 2).

I found Jason in more or less the same spot every time I entered this office - hidden behind the big wooden cubicle partition working at his computer. I would describe him as 'zoned-in' to his research, projects, emails, or thesis writing, oblivious to the goings-on outside the big wooden door. His office companions would come and go at various times, but Jason was fairly consistently in the office, arriving at half-past seven in the morning and departing around six in the afternoon. Above his computer were three bookshelves stacked on top of each other. The top shelf, which held two lever-arch files, was barely used; the middle shelf supported a large stack of papers held in manila folders and a red tray full of mini test tubes containing soil samples; and the bottom shelf held many of Jason's most frequently used work-related possessions and his most treasured academic books.
Looking through some of the books on Jason's bookshelf, one would see biology and chemistry textbooks, a thesaurus, a science dictionary, and a whole host of botanical and zoological field guides representing South African plant biomes, and a variety of foreign plant biomes that Jason has encountered in his travels around the world. Jason also has a whole host of non-academic books sitting in large brown boxes beneath his desk. As we were conversing one day, Jason told me that there was an unofficial and unspoken competition happening between him and one of his office mates. The objective of this clandestine competition was to amass the most impressive book collection at one's desk. On one occasion, Jason indicated spontaneously that he takes great pride in his book collection, saying that one could "get a sense of who he was by what he was reading".

In my fieldnotes, I recorded a rather peculiar utterance from Jason referring to his office space as his 'officialdom'. On one of the days Jason and I spent together, through casual conversation I interrogated the idea of 'officialdom' and discovered that this word represented the level of respect he perceived himself to have within the academy and beyond as a result of having a dedicated working space. As a PhD student in the biological sciences, an office on campus was 'expected'. Furthermore, it was a space to be valued - symbolizing the fact that the hard work invested in becoming an academic had paid dividends.

The most important item on his desk 
was his computer - which was surrounded by blue paper trays, stacks of papers, and any other equipment or reference items he was using at the time. During much of my fieldwork spent with Jason in his office space, he would be hard at work on his computer. Rather than sitting and intrusively looking over his shoulder the whole time, I would sit and work on my laptop as well, occasionally glancing up to see if anything new or interesting had happened. One Tuesday morning in July, Jason and I were taking a momentary work break and bantering about important workplace possessions; I cheekily asked: "if your office was on fire, and you could only save one item... what would it be?” Jason replied:

It would be my computer, without a doubt... because the data on that computer [is being used] towards my $\mathrm{PhD}$, and it means more to me than any of my books would. I couldn't replace that data... it's my life's work and would be a tremendous set-back.

The atmosphere in the shared office space was described by Jason as "convivial" - Jason and his office mates had good working relations. He often recollected instances where he had consulted with his colleagues on research matters, imparting advice or insight. However, barring the odd joke or inquiry about weekend activities, I did not witness such collaboration. By and large, I would describe Jason's shared office arrangement as having both sociopetal and sociofugal elements. Sociopetal describes an intentional arrangement of people so that they can see and interact with other people, while a sociofugal arrangement of people allows each to maintain some privacy from the others (Hall 2012). Each workstation is positioned so that the person sitting at the desk is facing the wall and is separated from the next person by a large wooden cubicle partition. On the one hand, these workstations foster a social arrangement that is individualistic. On the other hand, the shared office space also fosters a degree of comradery and collegiality between the office occupants. Jason valued this aspect of the shared office.

On occasion, someone would knock at the door needing to speak with one of the postgraduate students sitting inside the office. The reasons for the drop-ins included an academic supervisor needing to speak to a student about their latest draft submission; friends from across campus dropping in to say 'hello'; undergraduate students seeking advice for upcoming assignments; or fellow students requiring access to the laboratory at the end of the hallway. Jason would often be the first to pop his head around the cubicle partition, greet the visitor, and assist with their query, or to answer the office telephone which rang on the odd occasion. Based on my observations, the reason Jason attended to these enquiries more than his peers might be due to the fact that he was most often present. When Jason's office cohabitants were at hand, sometimes the question being asked by the visitor required an answer from someone who knew the University system intimately. Jason, having spent thirteen 


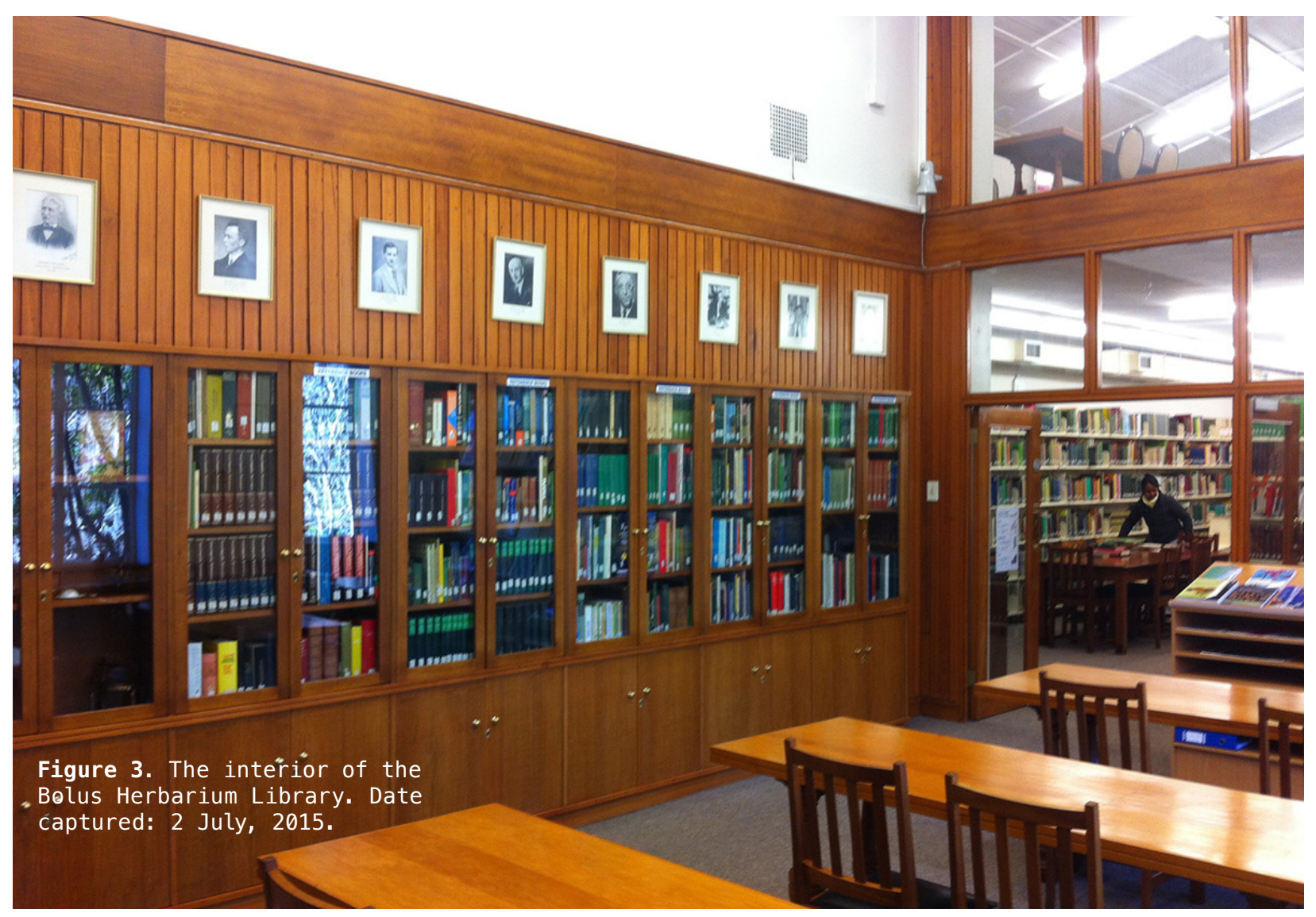

years of his life at the academy, often had the answer (or knew how to find it). One morning, I learnt to my amusement that the published telephone number for the University of Cape Town legal aid clinic was incorrect, and that many phone calls seeking legal advice were being directed to the shared telephone in this office. This was a source of great annoyance for Jason, who had tried on many occasions to rectify this error without success.

Late in the morning of the 2nd of July, Jason invited me to join him on a walking tour of the H.W. Pearson building to show me many of the other spaces where he worked, or had done work in the past. Jason and I climbed the stairs to Bolus Herbarium Library, a botanical library collection that the Univer82 JUE 7.1 2017 sity of Cape Town acquired through special bequest after the death of local businessman Harry Bolus in 1911. As we approached the double-doors at the entrance of the library, Jason scanned his student card to gain access to this space.

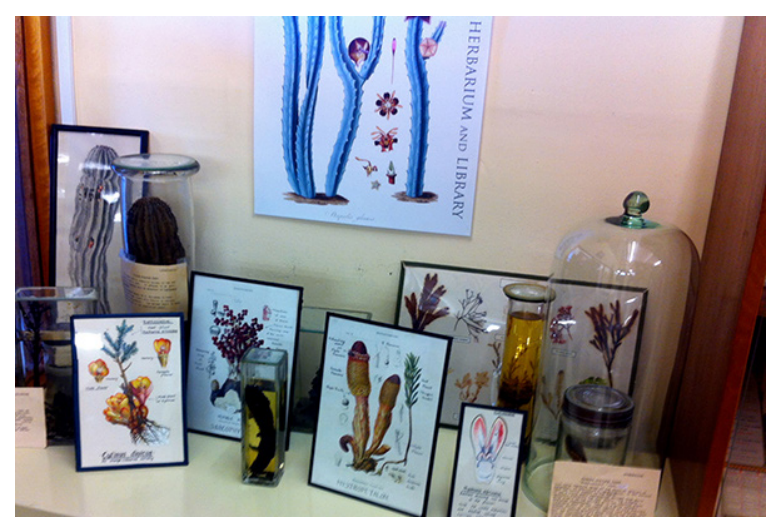

Figure 4. Inside the Bolus Herbarium. Many of the specimens on this table are preserved in formaldehyde and displayed alongside scientifically correct botanical illustrations. Date captured: 2 July,2015. 
Although in principle all University of Cape Town students have access to this library, only the Science Faculty students have security card access to this space. Students from other faculties require the assistance of the librarian to gain admission to this facility. Once Jason and I were inside the Bolus library, Jason presented some of the rare books that made this library unique and stated that on occasion he used this library as a point of reference for his own research (figure 3).

After the Bolus library, Jason and I wandered down the hallways to the Bolus Herbarium. The entrance to this facility is a set of wooden and glass double doors that are unlocked and open for any individual to enter. Immediately in front of these double doors is a desk with a collections curator ready to sign in people to gain access to the herbarium. Jason greeted the gentleman behind the desk and indicated that he was giving me a tour of the facilities in H.W. Pearson. We were granted admission to the herbarium by the curator without signing in. This was obviously Jason's 'officialdom' hard at work.

This fascinating place contains approximately 350,000 unique plant specimens - many of them flattened and pressed onto a stiff white piece of paper or preserved in formaldehyde (figure 4). Jason took me to a room in the adjacent Guthrie Herbarium and opened the nearest unlocked cabinet to exhibit some of the herbarium's botanical collection (figure 5). I asked how often he worked in this facility and Jason replied that at that moment he was not using the herbarium frequently, but had done so in the past. What workplace facilities he used was entirely dependent on where he was in the research process. As Jason and I were heading back to his office, Jason mentioned that he had also sometimes used the experimental glasshouse situated behind the H.W. Pearson building, and the laboratory space that occupied two large rooms at the end of the hallway outside his office. By the end of the tour, it became abundantly clear that Jason had access to a range of locations to conduct his academic endeavours.

To bring home this idea of the plurality of work places, on the 1oth of July, 2015, I joined Jason and his two undergraduate companions on a fieldwork expedition to Orangekloof in the Table

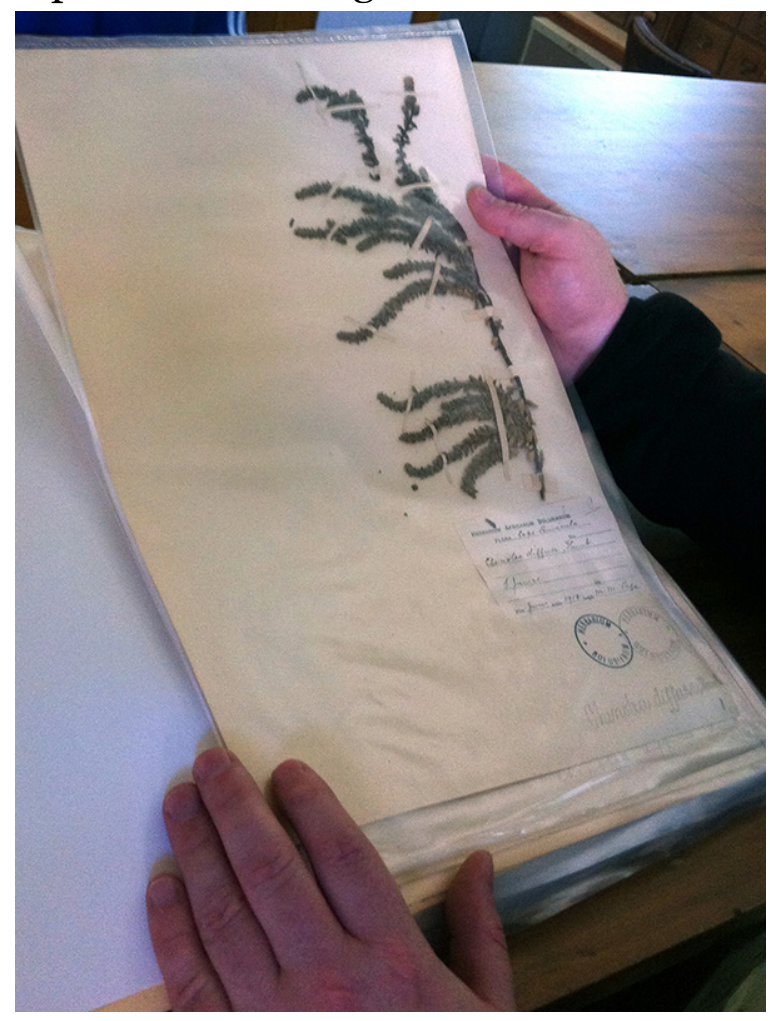

Figure 5. Jason exhibiting one of the botanical collections in the Guthrie Herbarium. Date captured: 2 July, 2015. 
intersected both forest and fynbos. ('Fynbos' is a Dutch word signifying a type of shrub land endemic to the Western Cape region of South Africa.) 'Percentage of cover' analysis usually started by using a measuring tape to cordon off twenty square meters of hillside to create a sample site. Once the borders of the site had been established, the biologists would start collecting 'eco scraps', or samples of plant foliage, from every visible plant specimen within this space, labelling each 'eco scrap' with masking tape and marker, and generating a list of plant species being recorded (figure 6).

After the first hour our little group settled into a routine. By this stage, I was also assisting Jason and his team by labelling 'eco scraps' and counting specimens for the percentage of cover analysis (figure 7). The four of us then tried to tally the population of each plant species we could visibly see within the sample site, in order to establish an estimated 'percentage of cover'. In a way, the percentage of cover analysis is like a population census for plants. This was no easy task as some of the hillside we were traversing was unstable and had a steep forty-five degree descent into the river valley below. Afterwards, the 'eco scraps' would be taken back to the laboratory where they would

Figure $7 . /$

I even participated i some of the fieldwor These are some of the 'eco scraps' we collected from the 'transitional zone' between fynbos and forest. Date captured: 10 July, 2015. 
be formally identified using field guides and the herbarium as a point of reference.

Secondly, Jason and his fellow biologists used a handheld auger to collect soil samples from each of the three established field sites. These soil samples would be taken back to the laboratory and analysed for traces of charcoal. The researchers were doing this analysis to look for recent signs of fire in the Orangekloof valley. Their hypothesis was that the vast tracts of Afromontane forests in the valley had flourished as a result of the deliberate attempt by the national parks board to prevent fire in the area for the past several decades. Once the four of us were finished collecting the samples, we packed up our camp, headed back down the hill, and Jason drove the bakkie back to the University of Cape Town. On route, we described our plans for the upcoming weekend.

August 4th was my last day of field research with Jason. I walked into the office and found him working away at his computer as I had witnessed many times over the prior weeks. I set up my laptop and began working. A few minutes later, Jason turned around and the pair of us began conversing about the fieldwork experience we shared a few weeks before. Jason indicated that he had spent many more days in the field since the day I joined him and his colleagues. At first, he was under the impression he was only involved in an advisory role, but after several discussions with his supervisor, he found ways to incorporate this fieldwork into his $\mathrm{PhD}$ research question. A few minutes later, Jason and I got up to go for a walk and made our way to the laboratory at the end of the hallway. This laboratory is a dedicated space for Jason, his colleagues, and his supervisor to use for their research - Jason gained access to this space using a key that he specifically had been given by his supervisor. Within this laboratory, one of Jason's undergraduate fieldwork companions was busy working with the soil samples taken from the Orangekloof field sites.

Several glass beakers were lined up in rows on the laboratory counter, filled with a concoction of water and soil. On the floor sat giant plastic buckets of muddy water. While in the laboratory, Jason and his colleague collaborated for the best part of forty-five minutes establishing the best way to extract charcoal from the soil samples being analysed. It became clear from the tone of this conversation that Jason was embodying his role as a senior $\mathrm{PhD}$ student and providing guidance when and where he could. Shortly thereafter, Jason and I made our way back to the office; I packed my bags, and left Jason working at his computer.

\section{Analysis}

As an anthropology student, I could not have asked for a more exciting fieldwork experience - exciting because it afforded me my first opportunity to conduct independent ethnographic research. From this, I learnt how to bridge the gap between designing research and implementing, then adapting, one's methods and techniques to the fluid nature of the field. 
Similarly, this experience was exciting because I had the opportunity to work alongside colleagues in other faculties, and even join them on their own research endeavours.

At the beginning of this article, I referred to Bourdieu's (1989) idea that space is a system of relations. A more in-depth research engagement would be required to uncover the full network of relations embedded in space. However, a preliminary reading of the data presented in this ethnography allows one to appreciate how space mediates one's behaviour, and how that location that render a specific locale meaningful. As I have illustrated above, the activities of Jason's work occurs in a variety of places that extend far beyond the office place.

On the face of things, the material environment of Jason's office is bounded by four walls. It is a distinct place. In my field research, I found that no two offices are exactly alike. All occupants have agency to choose their own possessions. All occupants dwell in their office in their own unique way. Furthermore, all occupants have their own logic underpinning

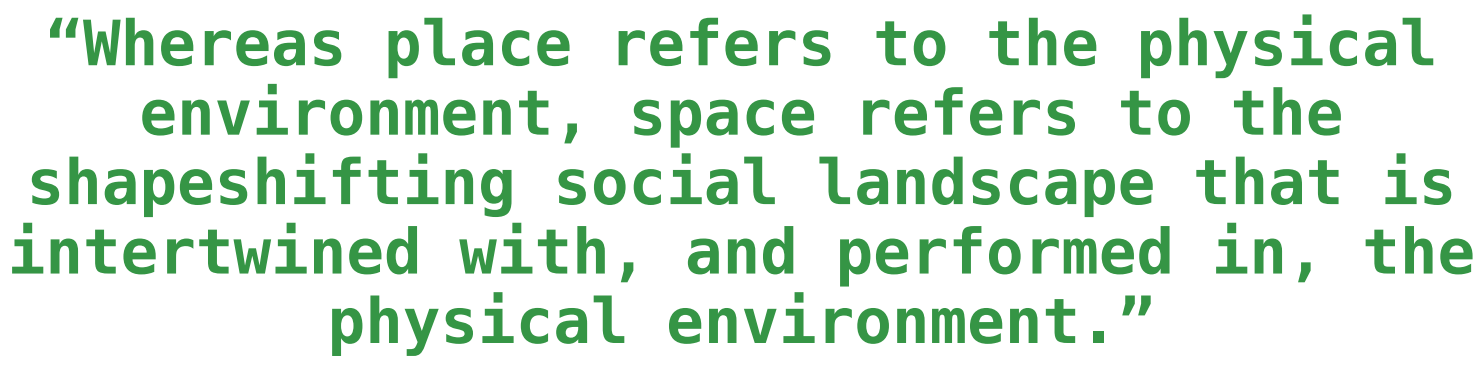

space informs one's relation to place. By observing Jason's office places and work spaces, and interpreting these observations through the theoretical lenses presented earlier in this essay, I can begin to show how space, place and people interweave in the context of an academic office.

The first theoretical lens I use to analyse my experience in the field is an amalgamation of Lefebvre's (1991) notions on space, and Casey's (1997) arguments in favour of place. I contend that space is the glue that holds a constellation of places together. Moreover, a place can be seen as the material environment plus the socially constructed spaces that occupy how they organise their possessions. This was clear in Jason's shared office in that each of his office-mates had his/her own distinct office cubicle - personalised, occupied, and used in different ways and at different times. These places and possessions aid in the everyday social process of work. As indicated at the beginning of this article, Jason regards his office as his base and point of consolidation. Jason perceives that all of his work stems from this geographic position.

Whereas the office is a place, the social activity of work has a far more space-oriented character. Lefebvre (1991) argues that space is permeated with social relations; it is active, ever-chang- 
ing, and infused with a multitude of other spaces. Whereas place refers to the physical environment, space refers to the shapeshifting social landscape that is intertwined with, and performed in, the physical environment. In this sense, I argue that the scientific disciplinary workspace enabled Jason to unlock a whole host of other places beyond his office. I had the opportunity to witness Jason working in his office, in the laboratory, and in the field at Orangekloof. Furthermore, Jason indicated that he may work from time to time in the library, the glasshouse or the Herbarium. In essence, work as a spatial activity brings this collection of places into focus.

Going back to my second point regarding the phenomenological notion of embodiment and Miles Richardson's (2012) ideas of being-in-the-world; Jason embodies place in two immediately recognizable ways. The most salient way Jason embodied his office place was through the idea of 'officialdom'. I interpret Jason's 'officialdom' as the embodiment of the office as a status symbol, the reification and realization of his hard work and dedication to his studies over the thirteen years he has been at the University of Cape Town, and perhaps his idea of the way the university body values and recognizes his research contribution. To Jason, the office is a critical fixture in his everyday work experience. The office is part of who Jason is, it validates his status, and authorises him.

The second way Jason embodies the material world of the office landscape is closely linked to Miles Richardson's (2012) theory of being-in-the-world. As Jason moves from place to place while working, he perceives and embodies the material culture in his immediate geographic place, and this informs his embodied behaviour. Referring back to the introduction of this essay, the idea of the office is culturally ubiquitous most people learn throughout their lives more-or-less what an office consists of. A bookshelf, books, a chair, a computer, a printer, a place to keep your important possessions, and a place to work - the office is reflected through material culture and in turn when a person experiences this place, one perceives and reacts in a socially appropriate manner. Behaviour then becomes routinized and deemed appropriate for that place.

Likewise, the same scenario may be true for the ensemble of other places Jason goes to throughout his work day, such as the Bolus Library, the Bolus Herbarium, the laboratory, or the field. Here, I am not arguing that being-in-the-office is the same for all people. Sometimes people may react slightly differently, or so differently that their behaviour may be considered out-of-place. The point is, on a subconscious level - all people, including Jason, perceive and embody their workspace.

To refine this office place vis-à-vis work space relationship even further, our third theoretical lens draws inspiration from Ingold's (2000) idea of the taskscape. As stated previously, 'work' is a catch-all term that needs to be analysed 
more deeply. Being-in-the-office for Jason involves an ensemble of tasks which are inherently related to his geographic position in the office landscape. For instance, much of my time spent in the field with Jason was spent watching him work at his computer - writing his doctoral dissertation, journal articles, and working on presentations. Writing is a very specific task, situated in a very specific spot in Jason's office landscape. Likewise, the task of research may be situated in the laboratory, the library, and the field.

Being-in-the-office in the Orangekloof field site presents a whole host of other tasks related to scientific analysis - measuring, observing, and collecting samples. Likewise, being-in-the-office in the laboratory requires the tasks of experimentation, analysis, and amalgamation of data. The library, the herbarium and the glasshouse can be incorporated into the taskscape as well; again, each place in Jason's office landscape presents its own unique set of tasks. Lastly, many of these tasks make up part of Jason's unique identity as a scientist within the university community - one would be hard-pressed to find an academic from the law faculty undertaking environmental field research in Orangekloof or working in the glasshouse. This taskscape is unique to the biological sciences.

As much as Jason might want to think that academia is a lonely life, his taskscape forms part of the fluid and dynamic social space that is the University of Cape Town. There are a multitude of other agents across the academic com- munity engaging in similar patterns of activity. Refer back to some of Jason's colleagues in his shared office - all of his office mates are senior postgraduate students conducting their own research to complete their respective degrees. They all have their own respective taskscapes which coincide with their respective research topics. In some instances their ensemble of tasks may intertwine with Jason's, and in some instances may diverge from it. In essence, my experience in the field corroborates Ingold's (2000, 325) argument that "tasks [make] up the pattern of activity of a community". From this understanding, the office place then becomes the point where this ensemble of tasks is consolidated, through writing, to form a piece of research. The end result will be that Jason's research will become the output required to complete his $\mathrm{PhD}$ and subsequent academic publications.

\section{Conclusion}

As an overarching theoretical framework, phenomenology is a fruitful and flexible approach for analysing people's interactions with place and space, including their everyday office places and work spaces.

Using the first theoretical lens, I draw on Lefebvre's (1991) construct of space, and Casey's (1997) argument in favour of place - and I argue in favour of both ideas. Through my experience with Jason, I show how both place and space are useful concepts. In essence, I argue that work is the performance of space that consolidates a variety of office places in a 
meaningful way. Concomitantly, place is the physical manifestation of built form and landscape given meaning by an array of social spaces present in any given context. In short, my research corroborates Casey's (1997) argument that 'space' and 'place' are equally important constructs.

In the second theoretical lens, I draw on ideas of phenomenological embodiment and Richardson's (2012) ideas of being-in-the-world to analyse how Jason embodies and reacts to the material culture and physical environment he is emplaced within at any given point in time. In the process of moving through his environment, Jason perceives and embodies the architecture and material culture around him. This process enables Jason to read his surroundings and informs his behaviour accordingly.

The third theoretical lens draws on Ingold's (2000) notions of the taskscape. I argue that the taskscape is the thread that strings all my data and literature together. Through my experience with Jason, I describe work as an ensemble of tasks. Jason walks from his office to the other places in his work landscape. In each new place he engages in a different task. Each task, or set of tasks, is am embodiment of place. As such, work, as a spatial activity, is interwoven into the office landscape.

Stemming from this discussion, one can start to understand that there is a specific way in which one's academic discipline disciplines space and shapes place; and that moving across spaces/ between places is akin to operationalising the discipline within the university. From this vantage point, movement across space becomes part of one's methodology. I have shown this process in action as Jason migrates from the office, to the laboratory, to the herbarium, and to the mountainside.

The key component to operationalising the academic discipline within the university is the office. The office is the central place from which one's taskscape flows. The office, the laboratory, the herbarium, and the mountainside all present the plant scientist with a unique set of tasks required to conduct scientific inquiry. Also, the academic office enables one to have easy access to one's disciplinary archive.

From this project, I have come to appreciate how powerful space is in mediating the performance and practice of everyday life, including that of 'work'. As a first point of departure for future research, I would like to revisit Bourdieu's (1989) idea pertaining to space as a system of relations. With a more in-depth investigation, might it be possible to map the full network of relations embedded within the space of an academic office?

As a second point of departure for future research, there is an aspect of the being-in-the-office that appears to elude the taskscape. The office is a critically important feature of the taskscape as it affords one a quiet place to cogitate, but at the same time the office can be a place for interacting with others. From this understanding, my question is this: is 'thinking' a task on an academic taskscape? 
For an academic dwelling in their office, there could be some aspects of thought that may be inherently task-like. However, there also appears to be an abstract component to sitting at one's desk and thinking that transcends the taskscape. Conversely, might the spaces of academic work be more complex when one includes the moments spent day-dreaming about research in the shower, or stressing about a submission deadline while commuting to work, or having that 'ah-ha' moment about how to word an essay while running on the treadmill at gym? One's relation to the spaces of work may not stop at the office door or at the conclusion of the working day. For some, the space of work may be a continual engagement that can be at least partially, or unintentionally, detached from place. I hope to carry on with ethnographic engagement with the space of work to further explore these ideas.

\section{Acknowledgements:}

I wish to express my deepest gratitude to the people I had the opportunity to engage with while in the field. I am very grateful for their hospitality and willingness to engage with my research and learning process. Furthermore, I wish to express appreciation for the guidance from my supervisors, Professor Carolyn Hamilton and Doctor Mbongiseni Buthelezi, both of whom have been the most amazing support structure. Finally, I would like to acknowledge and thank the University of Cape Town for the funding assistance which made this research possible. 


\section{Bibliography}

Anthropology Southern Africa. 2005. "Guidelines for anthropological research." Anthropology Southern Africa 28(3\&4): 142-144.

Applebaum, Herbert. 1992. The Concept of Work: Ancient, Medieval, and Modern. Albany, NY: State Uni versity of New York Press.

Baldry, Christopher. 1997. "The social construction of office space." International Labour Review 136(3): 365-378.

Bourdieu, Pierre. 1989. "Social space and symbolic power." Sociological Theory 7(1): 14-25.

Casey, Edward S. 1997. "Smooth spaces and rough-edged places: The hidden history of place." The Review of Metaphysics 51(2): 267-296.

Csordas, Thomas J. 2002. Body/Meaning/Healing. New York: Palgrave McMillan.

Garuba, Harry., and Sam Radithalo. 2008. "Culture." In New South African Keywords, edited by Nick Shepherd and Steven Robins, 35-46. Johannesburg: Jacana Media (Pty) Ltd.

Hall, Edward T. 2012. "Proxemics." In The Anthropology of Space and Place: Locating Culture, edited by Setha M. Low and Denise Lawrence-Zuniga, 51-73. 0xford: Blackwell Publishing.

Ingold, Tim. 2000. The Perception of the Environment: Essays in Livelihood, Dwelling and Skill. Abing don: Routledge.

Lefebvre, Henri. 1991. The Production of Space. Translated by Donald Nicholson-Smith. 0xford: Black well Publishing.

Lefebvre, Henri. 2009. State, Space, World: Selected Essays, edited by Neil Brenner \& Stuart Elden. Translated by Gerald Moore, Neil Brenner, and Stuart Elden. Minneapolis: University of Minne sota Press.

Low, Setha M. 2003. "Embodied space(s): Anthropological theories of body, space, and culture." Space \& Culture 6(1): 9-18.

Merleau-Ponty, Maurice. 2007. "From the phenomenology of perception." In Beyond the Body Proper: Read ing the Anthropology of Material Life, edited by Margaret Lock and Judith Farquhar, 133-149. London: Duke University Press.

Merrifield, Andrew. 2006. Henri Lefebvre: A Critical Introduction. Abingdon: Routledge.

Miller, Daniel. 2010. Stuff. Cambridge: Polity Press.

Nyamnjoh, Franics B. 2012. "Blinded by sight: Diving the future of anthropology in Africa." Africa Spectrum 47(2\&3): 63-92.

Phillips, Howard. 1993. The University of Cape Town: 1918-1948. Cape Town: University of Cape Town Press.

Relph, Edward. 1976. Place and Placelessness. London: Pion.

Richardson, Miles. 2012. “Being-in-the-market versus being-in-the-plaza: Material culture and the construction of social reality in Spanish America." In The Anthropology of Space and Place: Locating Culture, edited by Setha M. Low and Denise Lawrence-Zuniga, 74-91. 0xford: Blackwell Publishing.

Saval, Nikil. 2015. Cubed: A Secret History of the Workplace. New York: Anchor Books.

Schmahmann, Brenda. 2011. Bringing Cecil out of the closet: Negotiating portraits of Rhodes at two South African universities. De Arte. 84: 7-30.

Wallman, Sandra. 1979. "Introduction." In Social Anthropology of Work, edited by Sandra Wallman, 1-24. London: Academic Press.

1 About the Bolus Herbarium Library: http:// www.bolus.lib.uct.ac.za/bol/about-bolusherbarium-library.

2 For more information, see http://web.uct. ac.za/depts/bolus/.
This work is licensed under a Creative Commons Attribution-NonCommercialNoDerivatives 4.0 International License. 